\title{
Оптические и фотоэлектрические свойства кристаллов $\mathrm{ZnSe}: \mathrm{Ti}$
}

\author{
(C) Ю.А. Ницук, Ю.Ф. Ваксман \\ Одесский национальный университет имени И.И. Мечникова, \\ 65082 Одесса, Украина \\ E-mail: nitsuk@onu.edu.ua
}

(Получена 16 августа 2016 г. Принята к печати 29 сентября 2016 г.)

\begin{abstract}
Проведены исследования спектров фотопроводимости и фотолюминесценции кристаллов $\mathrm{ZnSe}: \mathrm{Ti}$ в видимой и ИК-областях спектра. Установлено, что высокотемпературная примесная фотопроводимость кристаллов $\mathrm{ZnSe}: \mathrm{Ti}$ обусловлена оптическими переходами электронов с основного состояния ${ }^{3} A_{2}(F)$ на высокоэнергетические возбужденные состояния с последующим термическим переходом электронов в зону проводимости. Эффективное возбуждение внутрицентровой люминесценции кристаллов $\mathrm{ZnSe}: \mathrm{Ti}$ осуществляется светом из области собственного поглощения ионов $\mathrm{Ti}^{2+}$.
\end{abstract}

DOI: 10.21883/FTP.2017.05.44413.8388

\section{1. Введение}

Кристаллы селенида цинка, легированные переходными металлами, получили широкое применение в качестве материалов для активных сред и пассивных затворов лазеров среднего ИК-диапазона. Наиболее исследованными из этой группы являются кристаллы $\mathrm{ZnSe}: \mathrm{Cr}$ и $\mathrm{ZnSe}: \mathrm{Fe}$, на основе которых реализована эффективная лазерная генерация $[1,2]$. Кристаллы $\mathrm{ZnSe}$ : Ti являются менее изученными по сравнению с другими кристаллами селенида цинка, легированными переходными элементами. Имеющиеся по этим кристаллам данные ограничиваются исследованиями парамагнитных свойств [3] и оптических свойств в средней ИК-области [4]. Одновременно с этим, расчеты, выполненные в работе [4], свидетельствуют о широком спектре энергетических состояний иона $\mathrm{Ti}^{2+}$ в кристаллах халькогенидов цинка. В связи с этим, исследования оптического поглощения, фотолюминесценции и фотопроводимости кристаллов $\mathrm{ZnSe}$ : Ti являются актуальными.

В данной работе исследована и идентифицирована структура спектров оптического поглощения, люминесценции и фотопроводимости кристаллов $\mathrm{ZnSe}: \mathrm{Ti}$ в видимой и ИК-областях спектра. Показано наличие полос оптического поглощения, люминесценции и фотопроводимости, обусловленных присутствием примеси титана.

Цель данной работы заключается в идентификации спектров оптического поглощения, люминесценции и фотопроводимости кристаллов $\mathrm{ZnSe}: \mathrm{Ti}$ в видимой и ИК-областях.

\section{2. Методика эксперимента}

Исследуемые образцы были получены методом диффузионного легирования титаном исходно чистых монокристаллов $\mathrm{ZnSe}$. Нелегированные кристаллы были получены методом свободного роста на подложке монокристаллического $\mathrm{ZnSe}$, ориентированной в плоскости (111). Преимуществом диффузионного легирования является возможность получать заданные концентрации примеси и профиля легирования. Легирование кристаллов осуществлялось путем диффузии примеси из напыленного на поверхность кристалла металлического слоя титана в атмосфере $\mathrm{He}+\mathrm{Ar}$. Кристаллы отжигались при температурах 1170-1320 К. Длительность диффузионного процесса составляла 5 ч. После отжига кристаллы ZnSe : Ti приобретали светло-коричневый цвет в отличие от желто-зеленого цвета нелегированных образцов.

Спектры оптической плотности измерялись при помощи монохроматора МДР-6 с использованием дифракционных решеток 1200, 600 и 325 штр/мм. Первая из решеток использовалась для анализа спектров поглощения в интервале энергий фотонов 3-1.2 эВ, вторая - в интервале $1.2-0.6$ эВ, а третья - в интервале $0.6-0.3$ эВ. В качестве регистратора светового потока в видимой области спектра использовался фотоумножитель ФЭУ-100, в ИК-области - фототранзистор ФР-1П, работающий в режиме регистрации по переменному току. Спектры оптической плотности измерялись при температурах 77 и $300 \mathrm{~K}$.

Спектры фотолюминесценции в видимой и ближней ИК-областях измерялись с помощью призменного спектрографа ИСП-51. Регистрация излучения проводилась фотоэлектронным умножителем ФЭУ-100. Возбуждение люминесценции осуществлялось светодиодами Edison Opto Corporation с энергией квантов в максимуме излучения 3.1, 2.69 эВ и азотным импульсным лазером ИЛГИ-503 с энергией квантов 3.74 эВ. Для регистрации спектров фотолюминесценции в средней ИК-области использовался монохроматор МДР-6 с использованием дифракционныхрешеток 600 и 325 штр/мм. В качестве регистратора ИК-излучения использовался фототранзистор ФР-1П, работающий в режиме регистрации по переменному току.

Спектры фотопроводимости измерялись с использованием монохроматора МУМ-2 с дифракционной решеткой 1200 штр/мм. Источником света служила галогеновая лампа. Мощность светового потока лампы поддерживалась постоянной на различных длинах волн. Для исследования фотопроводимости на кристаллы наноси- 
лись омические индиевые контакты. Вжигание индия осуществлялось при температуре $600 \mathrm{~K}$ с использованием вакуумной установки ВУП-4.

\section{3. Анализ спектров оптической плотности}

Спектры оптической плотности нелегированных кристаллов $\mathrm{ZnSe}$ при $77 \mathrm{~K}$ характеризуются краем поглощения с энергией 2.82 эВ. В области 2.75-2.80 эВ наблюдается полоса поглощения, обусловленная экситонами, испытывающими неупругое экситон-экситонное взаимодействие [5]. В области 0.40-2.6 эВ никаких особенностей спектров поглощения нелегированных кристаллов не обнаружено.

Легирование кристаллов титаном приводит к смещению края поглощения в сторону меньших энергий. Это смещение увеличивается с ростом температуры отжига. В табл. 1 приводятся величины смещения ширины запрещенной зоны $\left(\Delta E_{g}\right)$ кристаллов $\mathrm{ZnSe}$, легированных титаном. По величине смещения ширины запрещенной зоны рассчитывались концентрации титана в исследуемых кристаллах (см. табл. 1). Для расчета использовалось соотношение, используемое ранее для расчета концентрации примесей переходных металлов в кристаллах $\mathrm{ZnSe}$ [6]. Максимальное значение концентрации титана составило $6 \cdot 10^{19} \mathrm{~cm}^{-3}$ в кристаллах, полученных при 1320 К. Данное значение концентрации на 2 порядка выше, чем в кристаллах, легированных титаном в процессе выращивания [7].

В видимой области спектры оптической плотности кристаллов $\mathrm{ZnSe}$ : Ti характеризуются серией слабо разрешимых линий (рис. 1). Поглощение света в этой области увеличивается с ростом концентрации титана. В спектре поглощения слабо легированных кристаллов $\mathrm{ZnSe}: \mathrm{Ti}$ с концентрацией титана $7 \cdot 10^{17} \mathrm{~cm}^{-3}$ при температуре измерений $77 \mathrm{~K}$ выделяются шесть линий поглощения: $1.80,1.85,2.14,2.35,2.56,2.63$ эВ (рис. 1, кривая 1). При увеличении степени легирования положение этих линий не изменялось (рис. 1, кривые 2,3). Исследования оптической плотности в температурном диапазоне $77-300 \mathrm{~K}$ показали, что положение этих линий не изменялось. Таким образом, указанные линии

Таблица 1. Оптические характеристики кристаллов $\mathrm{ZnSe}: \mathrm{Ti}$ в области края поглощения

\begin{tabular}{c|c|c|c|c}
\hline $\begin{array}{c}\text { № } \\
\text { образца }\end{array}$ & Тип кристалла & $E_{g}$, эВ & $E_{g}$, мэВ & $N, \mathrm{~cm}^{-3}$ \\
\hline 1 & ZnSe исходный & 2.82 & - & - \\
2 & $\mathrm{ZnSe}:$ Тi, отжиг $1170 \mathrm{~K}$ & 2.79 & 30 & $7 \cdot 10^{17}$ \\
3 & $\mathrm{ZnSe}:$ Тi, отжиг $1220 \mathrm{~K}$ & 2.77 & 50 & $4 \cdot 10^{18}$ \\
4 & $\mathrm{ZnSe}:$ Тi, отжиг $1270 \mathrm{~K}$ & 2.75 & 70 & $10^{19}$ \\
5 & $\mathrm{ZnSe}:$ Тi, отжиг $1320 \mathrm{~K}$ & 2.69 & 130 & $6 \cdot 10^{19}$
\end{tabular}

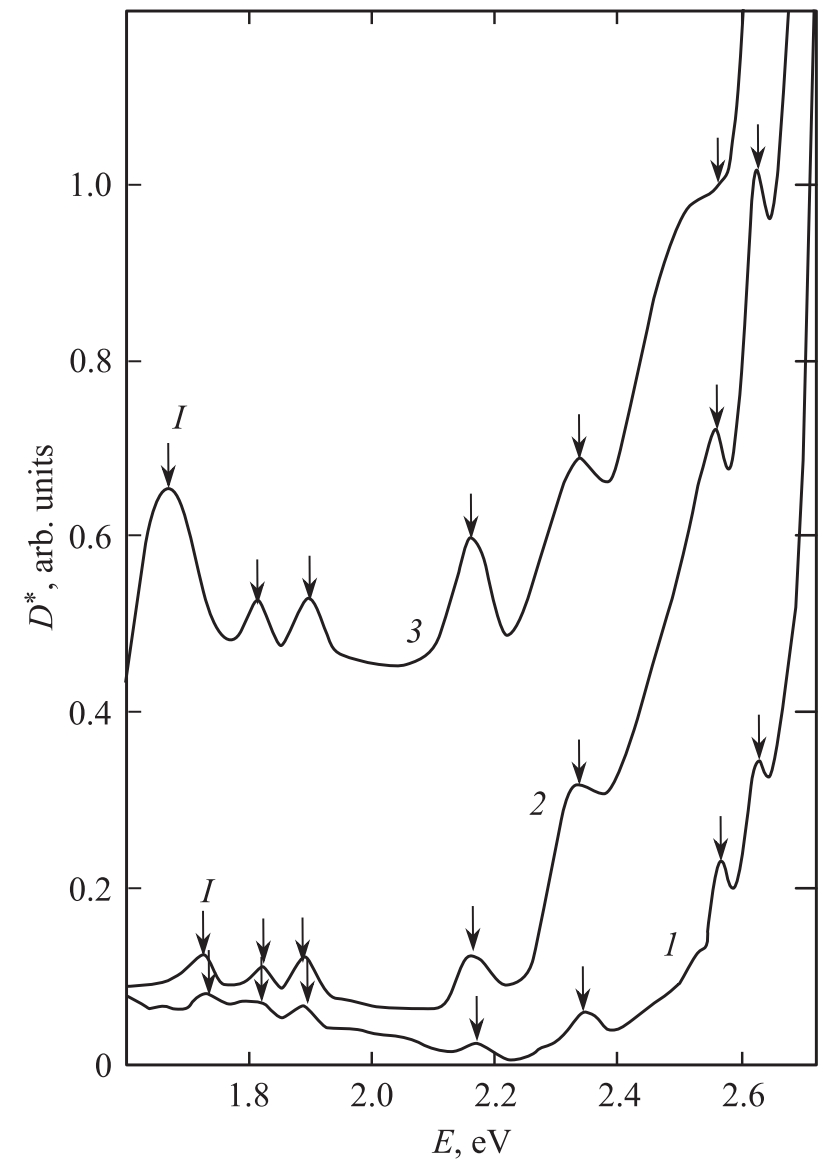

Рис. 1. Спектры оптической плотности в видимой области кристаллов $\mathrm{ZnSe}$ : Тi. Образцы: 2 (1), 4 (2) и 5 (3). $T_{\exp }=77 \mathrm{~K}$.

поглощения обусловлены внутрицентровыми переходами. Такое поведение линий поглощения также свидетельствует об их внутрицентровой природе. В табл. 2 приведены энергии оптических переходов в пределах иона $\mathrm{Ti}^{2+}$ и их идентификация. Эта таблица построена на основе наших экспериментальных результатов и расчетов энергетических состояний иона $\mathrm{Ti}^{2+}$ в $\mathrm{ZnSe}$, выполненных по диаграммам Танабе-Сугано [8]. Для расчетов были использованы параметры кристаллического поля $\Delta=3750 \mathrm{~cm}^{-1}$ и $B=700 \mathrm{~cm}^{-1}$, полученные в работе [4]. Видно, что имеет место хорошее совпадение экспериментальных и рассчитанных результатов.

С увеличением концентрации титана до $10^{19} \mathrm{~cm}^{-3}$ в спектрах оптической плотности кристаллов $\mathrm{ZnSe}: \mathrm{Ti}$ отчетливо проявляется линия поглощения на 1.72 эВ (I-полоса). С увеличением концентрации примеси титана до $6 \cdot 10^{19} \mathrm{~cm}^{-3}$ данная полоса поглощения смещается в область меньших энергий на 60 мэВ (рис. 1, кривая 3). Величина смещения совпадает с изменением ширины запрещенной зоны в этих кристаллах (см. табл. 1). При увеличении температуры от 77 до $300 \mathrm{~K}$ I-полоса смещается в область меньших энергий на 140 мэВ. Такое смещение соответствует температурному изменению ширины запрещенной зоны селенида цинка. Согласно 
Таблица 2. Оптические и фотоэлектрические переходы в кристаллах $\mathrm{ZnSe}: \mathrm{Ti}$

\begin{tabular}{|c|c|c|c|c|c|}
\hline № & Переход & $E_{\mathrm{abs}}^{\mathrm{exp}},{ }{ } \mathrm{B}$ & $E_{\mathrm{abs}}^{\mathrm{th}},{ }^{\mathrm{g}} \mathrm{B}$ & $E_{\mathrm{PL}}$, эB & $E_{\mathrm{PA},}{ }^{\ni \mathrm{B}}$ \\
\hline 1 & ${ }^{3} A_{2}(F)+h v \rightarrow{ }^{2} E(D)+e^{-}$ & - & - & - & 2.43 \\
\hline 2 & ${ }^{3} A_{2}(F) \rightleftarrows{ }^{1} T_{2}(G)$ & 2.63 & 2.67 & - & - \\
\hline 3 & ${ }^{3} A_{2}(F) \rightleftarrows{ }^{1} E(G)$ & 2.56 & 2.62 & 2.53 & - \\
\hline 4 & ${ }^{3} A_{2}(F) \rightleftarrows{ }^{1} T_{1}(G)$ & 2.35 & 2.34 & 2.29 & 2.35 \\
\hline 5 & ${ }^{3} A_{2}(F) \rightleftarrows{ }^{1} A_{1}(G)$ & 2.14 & 2.16 & 2.11 & 2.14 \\
\hline 6 & ${ }^{3} A_{2}(F) \rightleftarrows{ }^{3} T_{1}(P)$ & 1.85 & 1.86 & 1.82 & 1.85 \\
\hline 7 & ${ }^{4} T_{1}(F)+h v \rightarrow{ }^{3} A_{2}(F)+p_{\text {v.b. }}$ & 1.72 & 1.72 & - & - \\
\hline 8 & ${ }^{3} A_{2}(F) \rightleftarrows{ }^{1} T_{2}(D)$ & 1.80 & 1.82 & 1.77 & 1.79 \\
\hline 9 & ${ }^{3} A_{2}(F) \rightleftarrows{ }^{1} E(D)$ & 1.38 & 1.39 & 1.36 & - \\
\hline 10 & ${ }^{3} A_{2}(F) \rightleftarrows{ }^{3} T_{1}(F)$ & 0.76 & 0.76 & 0.7 & - \\
\hline 11 & ${ }^{3} A_{2}(F) \rightleftarrows{ }^{3} T_{2}(F)$ & 0.46 & 0.44 & - & - \\
\hline
\end{tabular}

данным работы [3], I-полоса поглощения может быть обусловлена фотоионизацией иона $\mathrm{Ti}^{+}$:

$$
\mathrm{Ti}^{+}+h v \rightarrow \mathrm{Ti}^{2+}+e_{\mathrm{v} . \mathrm{b}}^{+}
$$

Оптическое поглощение в ИК-области кристаллов $\mathrm{ZnSe}$, легированных титаном, характеризуется линиями поглощения на $0.46,0.76$ и 1.38 эВ (рис. 2). Изменение степени легирования и температуры кристаллов не

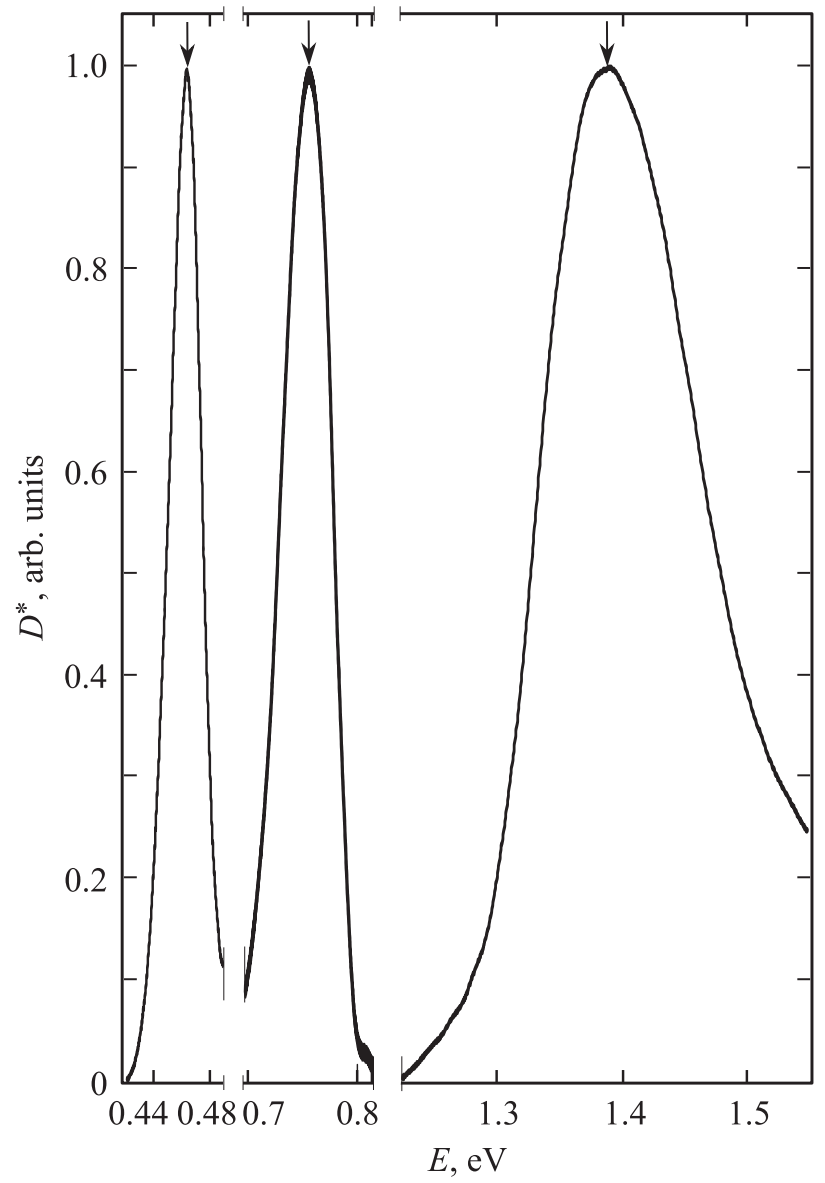

Pис. 2. Спектры оптической плотности в ИК-области кристаллов $\mathrm{ZnSe}:$ Ti. $T_{\exp }=77 \mathrm{~K}$. оказывало существенного влияния на положение данных линий поглощения, что является подтверждением их внутрицентровой природы. Согласно выполненным расчетам (см. табл. 2), первые две линии поглощения обусловлены переходами из основного ${ }^{3} A_{2}(F)$ состояния иона $\mathrm{Ti}^{2+}$ в близлежащие возбужденные состояния ${ }^{3} T_{2}(F)$ и ${ }^{3} T_{1}(F)$. Третья линия обусловлена переходами ${ }^{3} A_{2}(F) \rightarrow{ }^{1} E(D)$. Линия поглощения на 0.76 эВ наблюдалась ранее в работе [3].

\section{4. Исследование люминесценции кристаллов ZnSe : Ti}

Спектры фотолюминесценции кристаллов $\mathrm{ZnSe}: \mathrm{Ti}$ при $T=77 \mathrm{~K}$ характеризуются серией линий излучения на $0.7,1.36,1.77,1.82,2.11,2.29$ и 2.53 и 2.72 эВ (рис. 3). Интенсивность первых семи линий излучения увеличивалась с увеличением концентрации титана, а их спектральное положение оставалось неизменным. Такое поведение характерно для линий внутрицентрового излучения.

Как видно из табл. 2, наблюдаемые линии излучения коррелируют с исследованными линиями поглощения. Величина стоксового смещения линий люминесценции относительно соответствующих линий поглощения составляет 20-40 мэВ.

Линия излучения в области 2.72 эВ наблюдалась нами ранее и обуславливалась наличием экситонов, связанных на нейтральных вакансиях цинка [5].

Установлено, что относительная интенсивность линий внутрицентровой люминесценции $\mathrm{ZnSe}$ : Ti существенным образом зависит от энергии квантов возбуждающего света. Свечение с наименьшей интенсивностью возбуждается лазером с энергией квантов 3.74 эВ. Максимальная интенсивность излучения достигается при возбуждении светодиодами с $E_{\mathrm{ex}}=3.1$ и 2.69 эВ (рис. 4, кривые 2,3). Это свидетельствует о том, что зоназонное возбуждение примесной люминесценции кристаллов $\mathrm{ZnSe}$ : Тi является малоэффективным. При изме- 


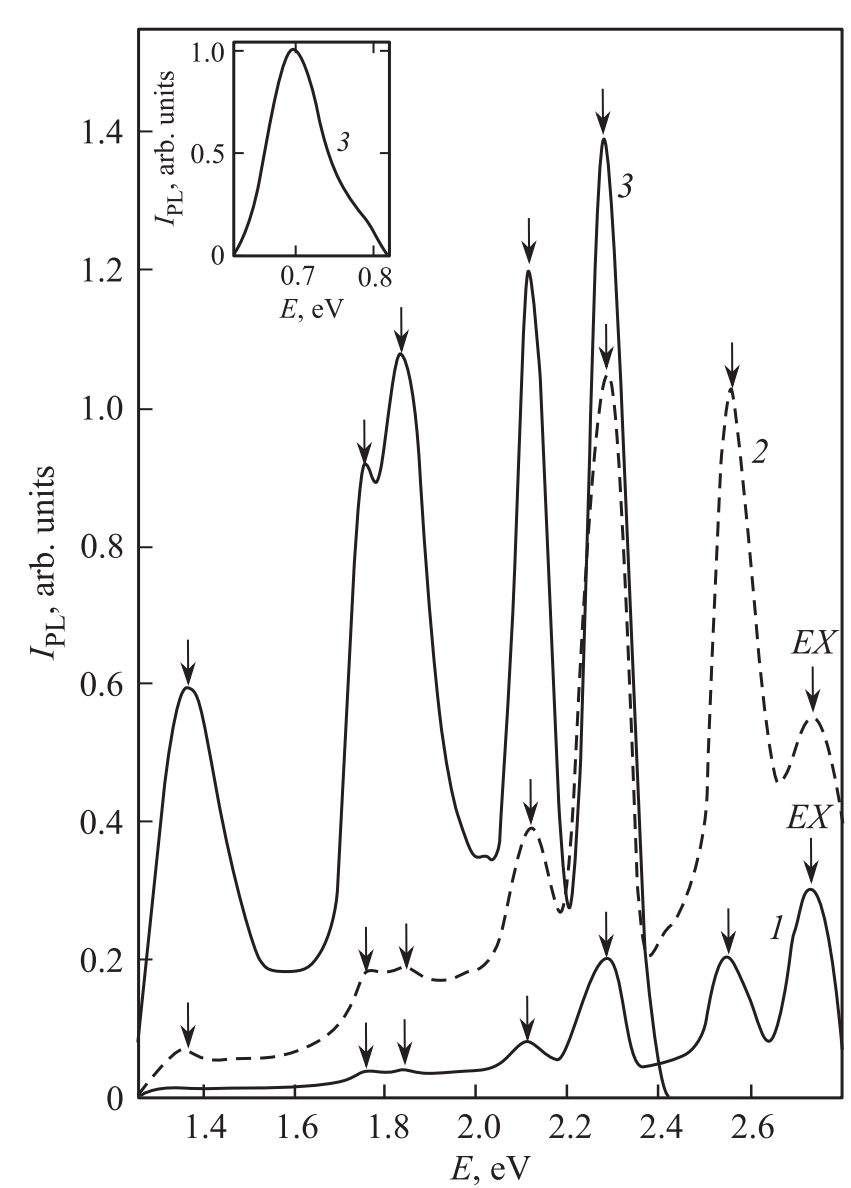

Рис. 3. Спектры фотолюминесценции кристаллов $\mathrm{ZnSe}: \mathrm{Ti}$. $E_{\exp }=3.74(1), 3.1(2)$ и 2.69 эВ (3). $T_{\exp }=77 \mathrm{~K}$. На вставке ИК-люминесценция при $E_{\exp }=2.69$ эВ.

нении энергии квантов возбуждающего света положение максимумов полос излучения не менялось.

\section{5. Анализ спектров фотопроводимости}

Нелегированные кристаллы $\mathrm{ZnSe}$ характеризовались одной полосой фотопроводимости с максимумом на 2.68 эВ при $300 \mathrm{~K}$. Эта полоса обусловлена межзонными оптическими переходами. При легировании титаном происходит смещение этой полосы в область меньших энергий. Величина этого смещения возрастает с увеличением концентрации титана и совпадает с изменением ширины запрещенной зоны, определенным по спектрам оптического поглощения (см. табл. 1).

Легирование титаном приводит к появлению дополнительных полос фотопроводимости в области энергий световых квантов 1.6-2.5 эВ (рис. 4, кривые 2,3). Интенсивность этих полос возрастает с увеличением концентрации титана. Можно выделить полосы 1.79 , $1.85,2.14,2.35$ и 2.43 эВ.

На рис. 4 представлены результаты исследований спектров фотопроводимости при различных темпера- турах. При $T=77 \mathrm{~K}$ во всех исследуемых кристаллах наблюдается только одна полоса межзонной фотопроводимости (рис. 4, кривая 1). При температурах $300 \mathrm{~K}$ и выше наблюдаются спектры примесной фотопроводимости (рис. 4, кривые 2,3).

При увеличении температуры от 300 до $400 \mathrm{~K}$ (рис. 4, кривая 3) полоса на 2.43 эВ (I область меньших энергий на 100 мэВ. Такое смещение соответствует температурному изменению ширины запрещенной зоны ZnSe. Остальные полосы примесной фотопроводимости не меняют свое положение с ростом температуры, что свидетельствует о внутрицентровом характере этих переходов. Кроме того, положение внутрицентровых полос хорошо совпадает с полосами оптического поглощения (см. табл. 2). Это свидетельствует о том, что указанные полосы фотопроводимости обусловлены теми же оптическими переходами, что и оптическое поглощение.

Процесс фотопроводимости в исследуемых кристаллах происходит следующим образом. $I_{1}$-полоса обусловлена оптическими переходами из основного состояния ${ }^{3} A_{2}(F)$ иона $\mathrm{Ti}^{2+}$ в зону проводимости (см. табл. 2). Соответствующие процессы можно представить следу-

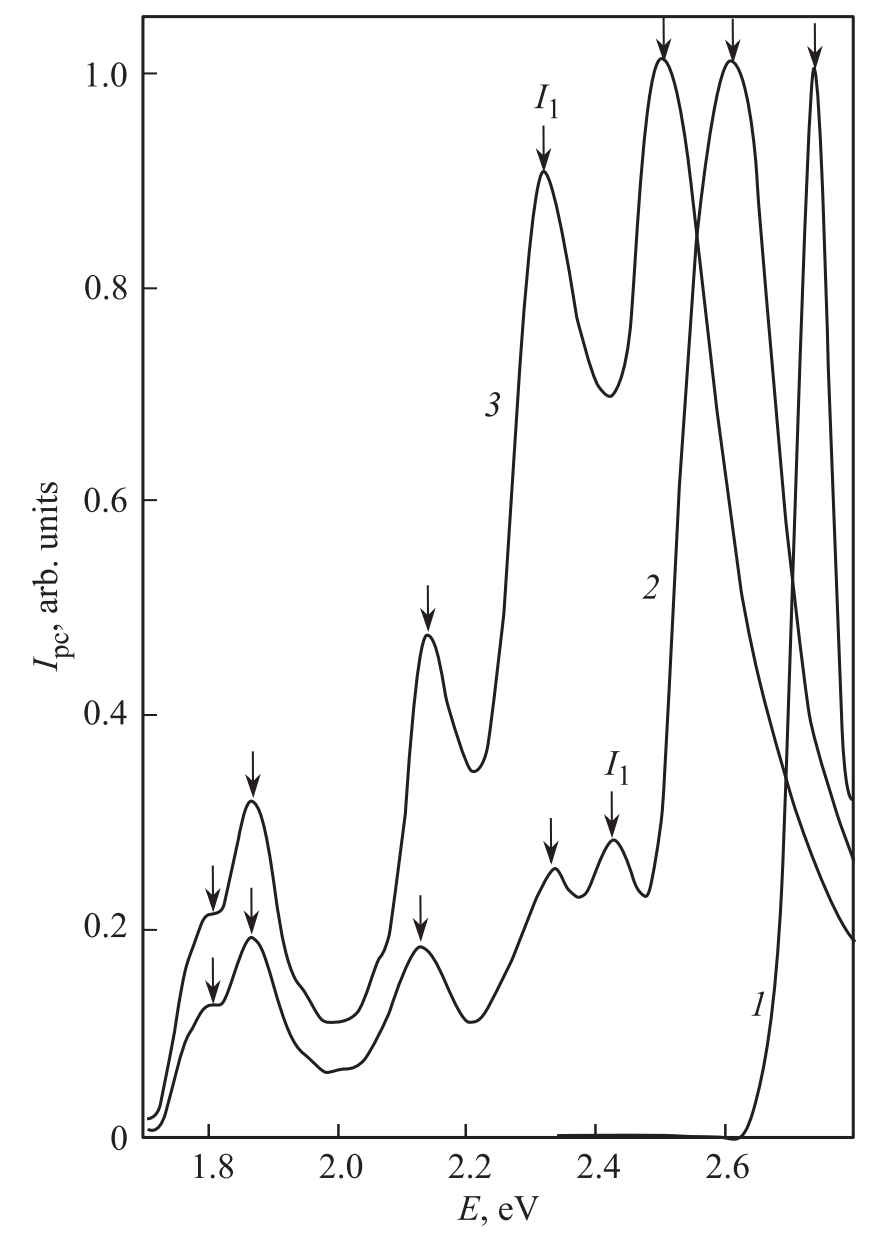

Рис. 4. Спектры фотопроводимости кристаллов $\mathrm{ZnSe}: \mathrm{Ti}$. $T_{\exp }=77(1), 300(2)$ и $400 \mathrm{~K}(3)$. 
ющим образом:

$$
\mathrm{Ti}^{2+}+h v \rightarrow \mathrm{Ti}^{3+}+e_{\text {c.b. }}
$$

Сравнение энергии максимума этой полосы фотопроводимости 2.43 эВ с энергией максимума полосы собственной фотопроводимости, равной 2.61 эВ для кристаллов $\mathrm{Ti}$ с концентрацией $10^{19} \mathrm{~cm}^{-3}$, позволяет заключить, что уровень основного состояния иона $\mathrm{Ti}^{2+}$ располагается на 180 мэВ выше потолка валентной зоны.

Остальные полосы фотопроводимости образуются благодаря двухстадийному процессу. Сначала происходят внутрицентровые оптические переходы электронов из основного состояния ${ }^{3} A_{2}(F)$ на более высокие возбужденные энергетические уровни иона $\mathrm{Ti}^{2+}$ (табл. 2). Затем происходит тепловой переход электронов из уровней возбужденных состояний в зону проводимости.

\section{6. Заключение}

Проведенные исследования позволяют сделать следующие выводы:

1. Показано, что высокотемпературная длинноволновая фотопроводимость кристаллов ZnSe : Ti обусловлена внутрицентровыми оптическими переходами, происходящими в пределах ионов $\mathrm{Ti}^{2+}$ с последующими тепловыми переходами электронов с уровней возбужденных состояний $\mathrm{Ti}^{2+}$ в зону проводимости.

2. Определена глубина залегания уровня основного состояния ${ }^{3} A_{2}(F)$ иона $\mathrm{Ti}^{2+}$, который располагается на 180 мэВ выше потолка валентной зоны.

3. Установлено, что легирование титаном приводит к появлению серии линий излучения в видимой области спектра. Обнаруженные полосы люминесценции кристаллов $\mathrm{ZnSe}: \mathrm{Ti}$ являются результатом внутрицентровых переходов в ионе $\mathrm{Ti}^{2+}$.

\section{Список литературы}

[1] V.V. Fedorov, S.B. Mirov, A. Gallian, D.V. Badikov, M.P. Frolov, Yu.V. Korostelin, V.I. Kozlovsky, A.I. Landman, Yu.P. Podmar'kov, V.A. Akimov, A.A. Voronov. IEEE J. Quant. Electron., 42 (9), 907 (2006).

[2] I.T. Sorokina, E. Sorokin, S.B. Mirov, V.V. Fedorov, V. Badikov, V. Panyutin, K. Schaffers. Optics Lett., 2002, 27, 1040 (2002).

[3] J. Dziesiaty, P. Peka, M.U. Lehr, A. Klimakow. Phys. Rew. B, 49 (24), 17011 (1994).

[4] H.F. Li, H.Q. Wang, X.Y. Kuang. Sci. China Phys., 54 (10), 1796 (2011).

[5] Ю.Ф. Ваксман, Ю.А. Ницук, Ю.Н. Пуртов, П.В. Шапкин. ФТП, 35 (8), 920 (2001).

[6] Ю.А. Ницук. ФТП, 48 (2), 152 (2014).

[7] A. Klimakow, J. Dziesiaty, J. Korostelin. Adv. Functional Mater., 3, 253 (1994).

[8] Дж. Хьюи. Неорганическая химия (М., Химия, 1987) c. 625 [Пер. с англ.: James Е. Huheey. Inorganic chemistry, (N.Y., Harper and Row, 1983)].

\section{Optical and photoelectric properties of ZnSe:Ti crystals}

\author{
Yu.A. Nitsuk, Yu.F. Vaksman
}

Odessa I.I. Mechnikov National University, 65082 Odessa, Ukraine

Abstract The photoconductivity and photoluminescence of $\mathrm{ZnSe}: \mathrm{Ti}$ crystals in the visible and IR-region of spectrum are investigated. It is shown that high-temperature impurity photoconductivity of $\mathrm{ZnSe}: \mathrm{Ti}$ crystals is caused by the optical transitions of electrons from the basic state ${ }^{3} A_{2}(F)$ to excited high-energy levels of $\mathrm{Ti}^{2+}$ ion with their subsequent thermal activation in the conduction band. The photoconductivity line conditioned by the photoionization of Ti impurity is founded. The effective excitation of $\mathrm{ZnSe}$ : Ti crystals intracenter luminescence is carried out by the light from the own absorption range of $\mathrm{Ti}^{2+}$ ions. 